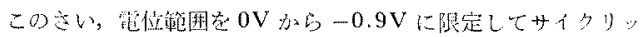

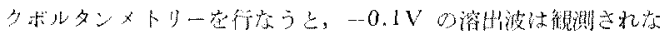

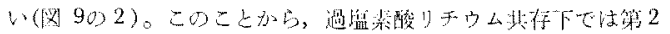

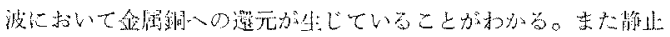

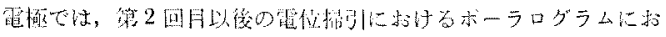

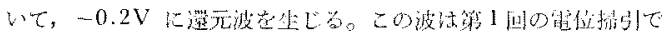

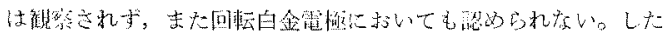

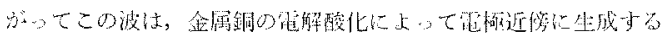

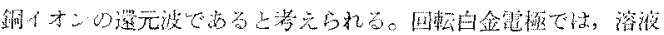

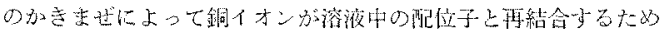

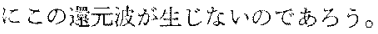

\section{4 まめ}

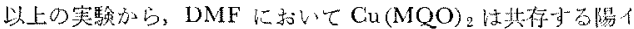

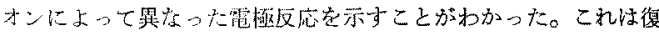

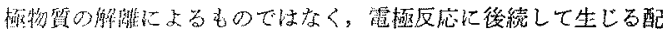

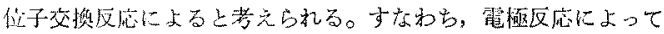
生じた $\mathrm{Cu}(\mathrm{MQO})_{2}-1$ インは $\mathrm{Et}_{4} \mathrm{NClO}_{4}$ 支持湓中では安定に存

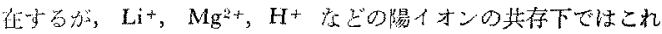

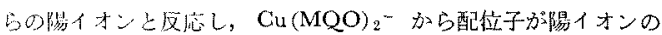

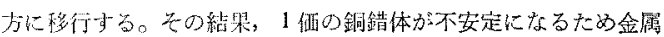

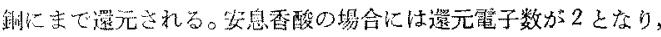

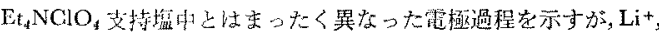

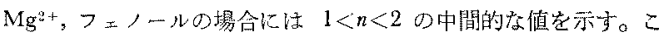

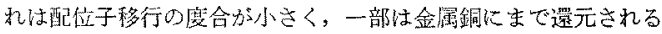

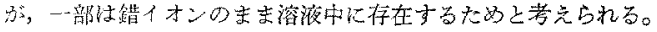

(1970 年 10 月，第 16 回ボーラログラフ討詇会発荠)

\title{
クレゾール異性体の陰イオン交換樹脂に対する挙動
}

(吸和 46 症 7 月 23 日要蝫)

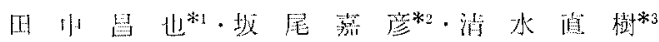

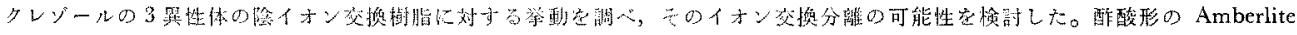

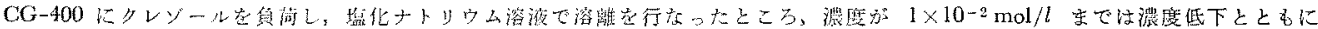

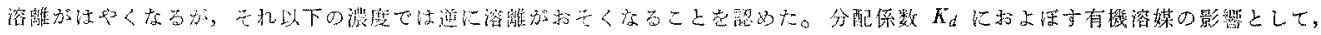

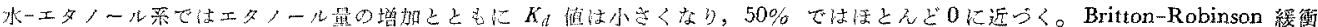

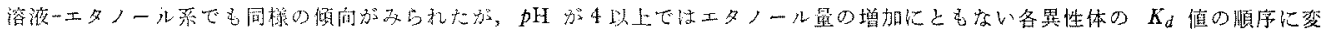

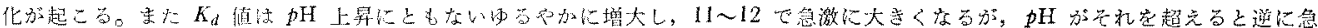

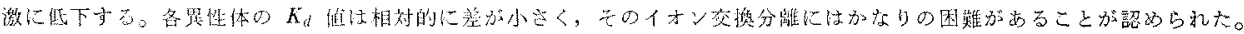

\section{1 緒}

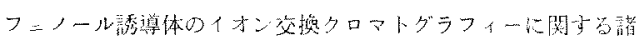

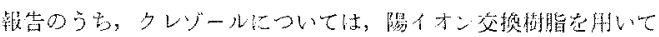

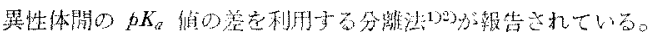

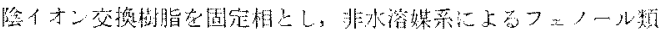

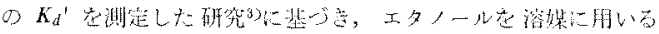

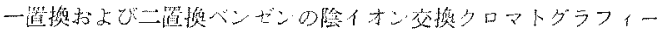

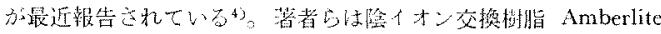

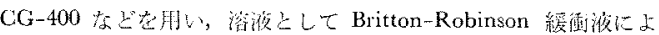

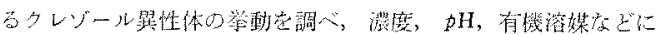

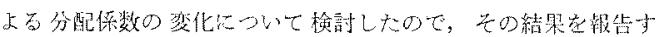

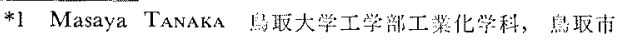
湖山闻

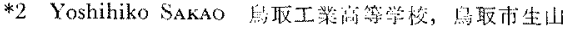

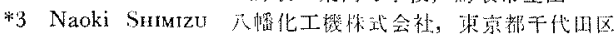
神田臣久閣时

1) J. Sherma, W. Rieman II, Anal. Chim. Acta, 18, 214 (1958).

2) 阅得一㽎, 日化, 75, 1297(1954),

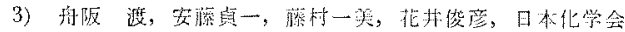
私, 22 年会洋演 (1969)

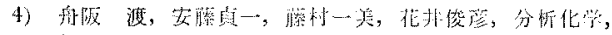
$20,427(1971)$
20

\section{2 实 験 方 法}

\section{1 陰イオン交換樹脂と試料}

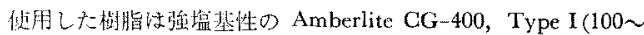

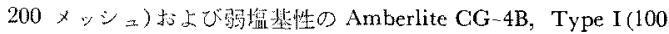

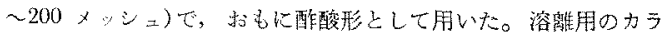

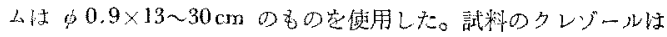

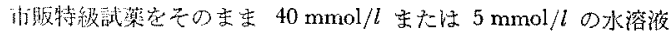

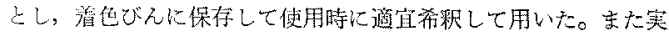

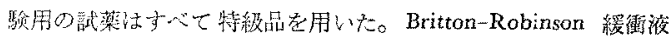
(以下 BRB) 子䀩記する)はリン酸，ホウ酸，和よび酷酸の各 0.5 $\mathrm{mol} / \mathrm{l}$ の水溶液尼混合し，水酸化ナトリウム溶液で $p \mathrm{H}$ を調整 Lt:

\section{2 测定方法}

2.2 .1 クレゾールの定量：クレゾールの定留は紫外吸光沈度

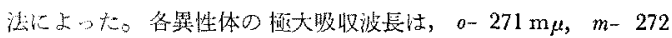
$\mathrm{m} \mu, p-277 \mathrm{~m} \mu$ で,この波長のしてで $1.0 \mathrm{mmol} / \mathrm{l}$ のあり

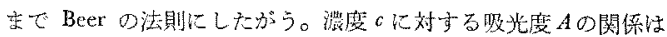

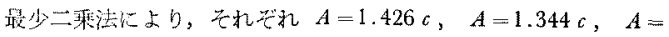
$1.544 c-0.003$ と見稍られる。

2.2 .2 分配係数 $\boldsymbol{K}_{d}$ : 重量分配係数 $\boldsymbol{K}_{d}$ の測定は主としてバ 


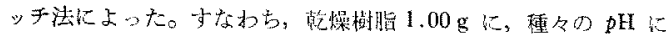

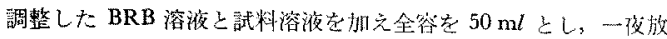
置ののちに上澄液中の買性体量它測定して $K_{d}$ 值老求的大。谷異

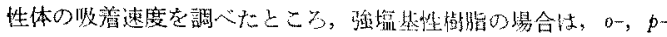

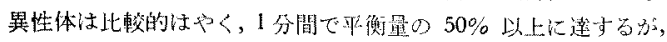

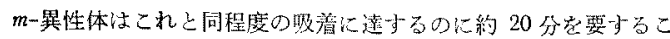
と夜認的大。

\section{3 結果および考察}

\section{1 吸光度と $\mathbf{p H}$ との関保}

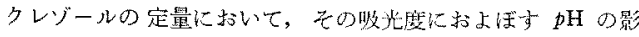

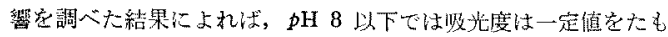
ち，それ以上の $p \mathrm{H}$ では低下する。したがって吸光度測定は酸 性側で行なった。

\section{2 電解質溶液に上る溶離}

クレゾールのような弱電解筫 ( $p K_{a}$ はてれぞれ 0- 10.287，m-

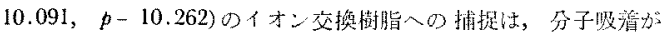

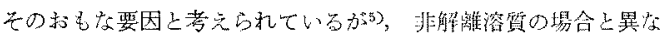

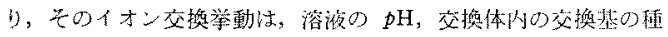

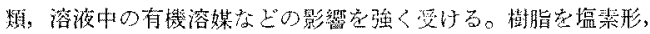

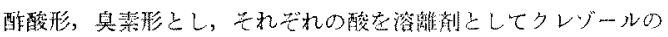

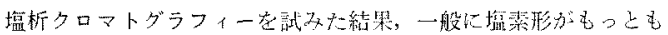

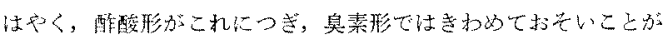

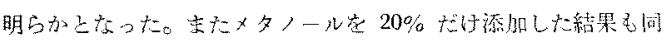

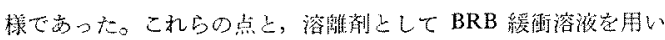
るとき其通のイオン形にすることが適当である点空考虑して，樹

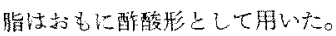

酶酸形の Amberlite CG-400にタレン゙ールを吸着され，增化

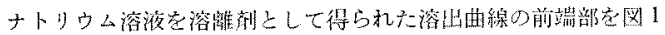
に㲎した。

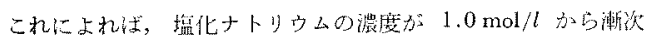

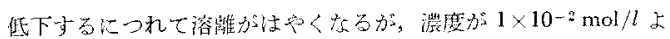

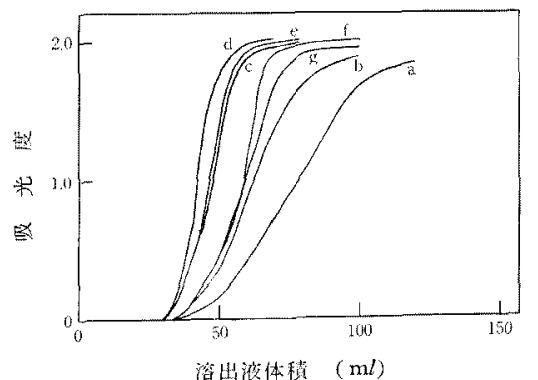

紧 脂: Amberlite CG-400, Type I( $\mathrm{OAc}^{-}$形) 試糊楮: $21.63 \mathrm{mg}$, 流速: $1 \mathrm{~m} / / \mathrm{min}$

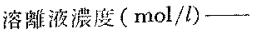

$a: 1.0, b: 0.5, \quad c: 0.2, d: 1 \times 10^{-2}$ e: $1 \times 10^{-3}, \quad$ f : $1 \times 10^{-4}, \mathrm{~g}: 1 \times 10^{-5}$

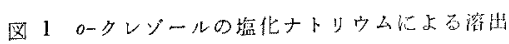

5) O. Samuelson, "Ion Exchange Separations in Analytical Chemistry", John Wiley \& Sons, New York (1963) p. 49.

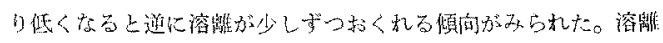

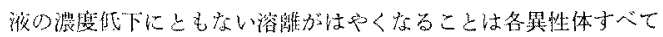

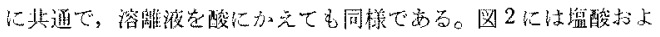

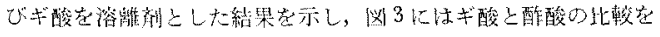
亦吉。

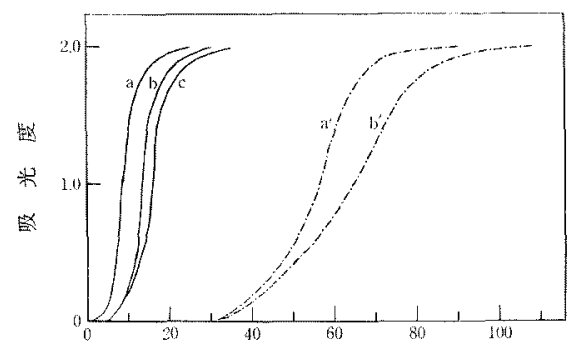

溶他液体精 $(\mathrm{m} l)$

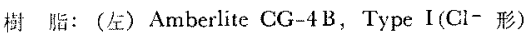
(右) 同上 $\left(\mathrm{OAC}^{-}\right.$形)

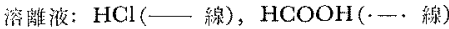
湠度 $(\mathrm{mol} / \mathrm{l})$

$\mathrm{a}: 0.01, \quad \mathrm{~b}: 0.05, \quad \mathrm{c}: 0.2$

$a^{\prime}: 0.01, \quad b^{\prime}: 0.04$

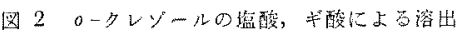

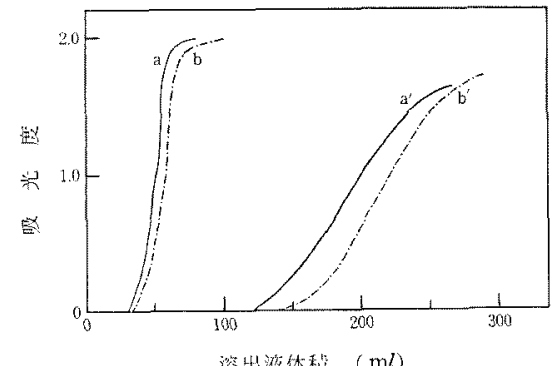

洔 脸: (t) Amberlite CG-4B ( $\mathrm{OAc}^{-}$形) (b) Amberlite $\mathrm{CG}-400\left(\mathrm{OAc}^{-} \mathrm{f}^{\prime}\right)$

觛料住: $21.63 \mathrm{mg}$ 流 㮫: $1 \mathrm{ml} / \mathrm{min}$ $\mathrm{a}, \mathrm{a}^{\prime}: 0.01 \mathrm{~mol} / \mathrm{l}$ 酰酸, $\mathrm{b}, \mathrm{b}^{\prime}: 0.01 \mathrm{~mol} / \mathrm{l}$ 斗酸

四 3 -

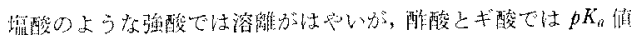
の大きい酶酸の力がややはやい。酢酸の場合には樹脂の活性基と

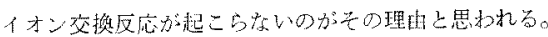

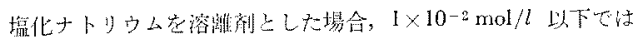

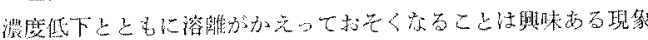

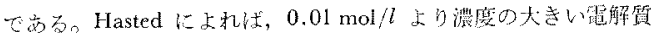

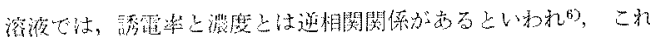

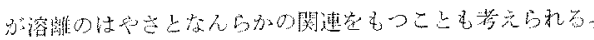

\section{$3.3 K_{\text {U }}$ におよぼす有機溶媒の影響}

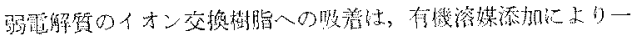

6) J. B. Hasted, D. M. Riston, C. H. Collie, J. Chem. Phys., 16, 11 (1948). 


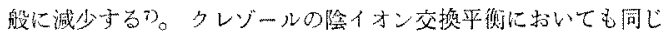

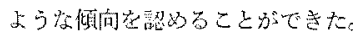

3.3.1 エタノール-水系: 酢酸形の Amberlite CG-400 につ

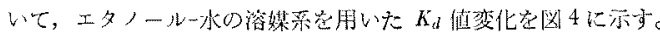

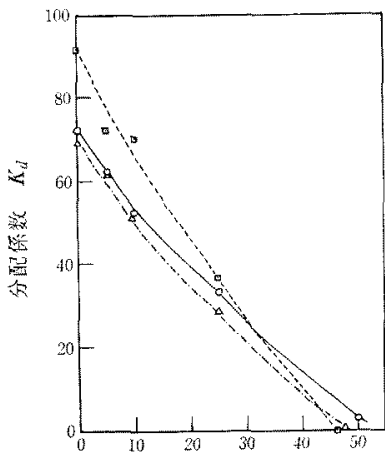

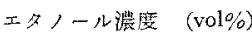

科脂: Amberlite CG-400, Type I ( $\mathrm{OAc}^{-}$形)

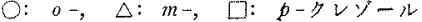

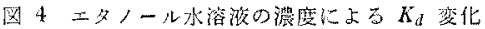

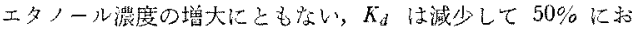
いてきとえど0に近くなる。したがってカラムクロマトグラフィ

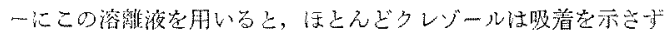

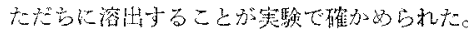

3.3.2 BRB 桵街液一エタノール系：BRE 綏㣫液江エ夕ノ一

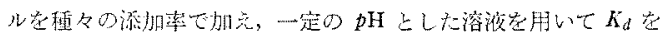

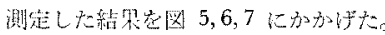

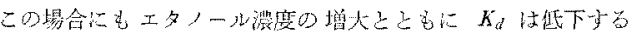

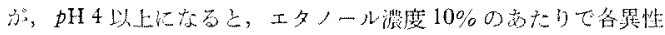

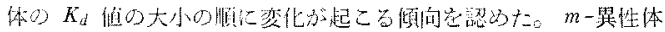

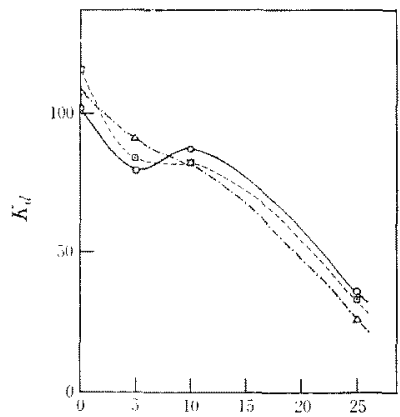

エ夕ノ一ル港加是 $(\mathrm{vol} \%)$

独 脂: Amberlite $\mathrm{CG}-400$, Type $1\left(\mathrm{OAc}^{-}\right)$形

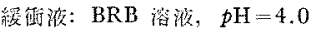

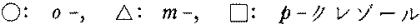

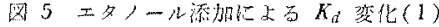

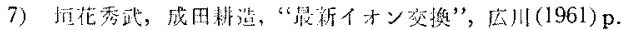
340.

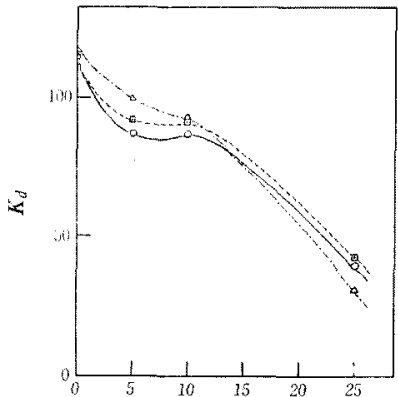

土タノ一几潦加量 ( vol \%)

檄 指: Amberlite CG-400, Type I(OAc- 形)

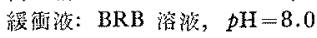

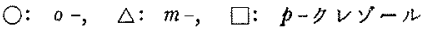

図 6 エタノ一ル添加に上る $K_{d}$ 変化 (2)

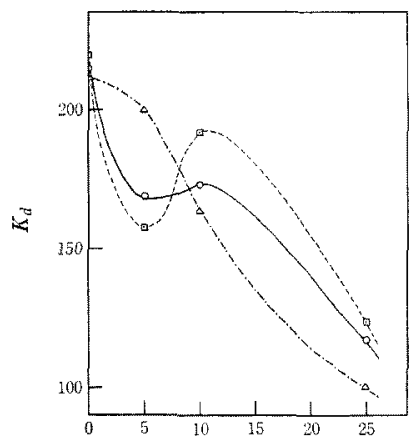

エ夕ノ一添加量 $(\mathrm{vol} \%)$

枓 脂: Amberlite CG-400, Type I(OAc-" 珠) 授雨滩： $\mathrm{BRB}$ 溶液， $\mathrm{pH}=10.0$

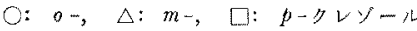

图 7 ×タノ一儿添加に上る $K_{d}$ 変化 (3)

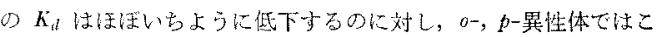

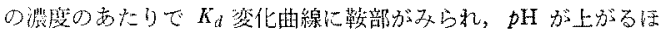

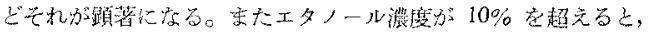

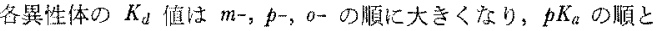

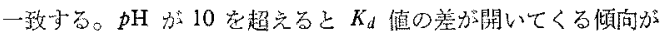

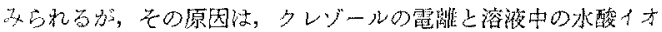
ンによる樹脂之の交換反応があずかってくるため已推定され，各

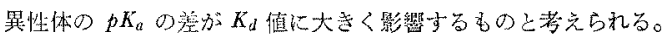

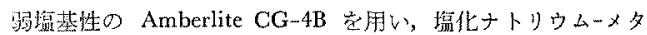
ノ一ル采で $K_{d}$ を測定した絬果も上さほぼ同様の傾向を示した。 イオン交㧰体からのクレゾールの脱䠊の速さを調ベるために， クレ゙゙ール在吸诣させた樹脂と各種溶液をいったえ平衡状態とし

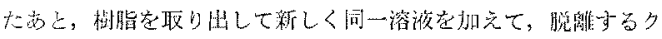

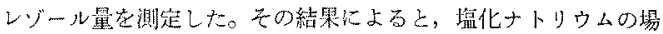

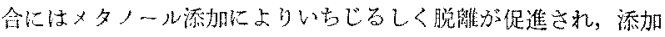

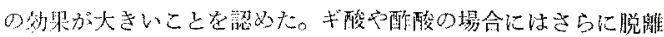

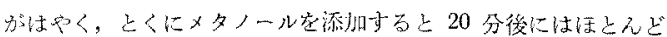
完全に脱跳された。このことからも，有機溶媒の添加は $K_{d}$ 檤を 
下げて溶踓をはやめる好㚌をむつことが明らかである。 $3.4 \boldsymbol{K}_{d}$ におよほす $p \mathbf{H}$ の影響

溶源の $p \mathrm{H}$ 变化に上る $K_{d}$ 㩁の変化を図 8 , 四 9 に亦した。

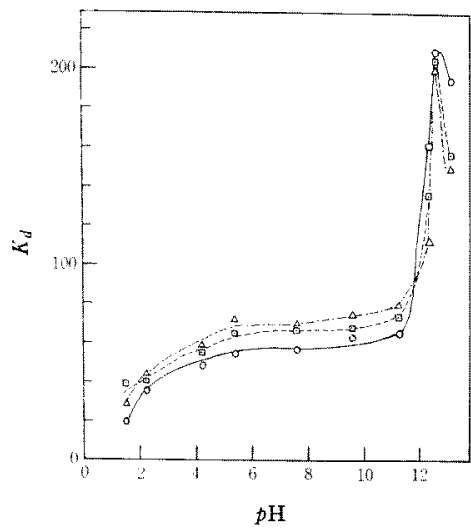

檴 期: Amberlite $\mathrm{CG}-400$, Type I(OAc ${ }^{-}$形)

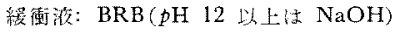

○: $0-, \quad \triangle: m-, \quad \square: p-タ レ y-ル$ 圂 8 p

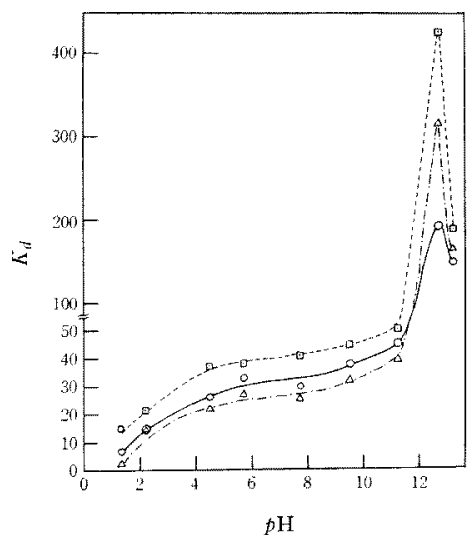

樹 踓: Amberlite CG-400, Type I(OAc- 形)

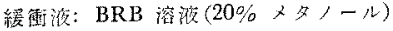
(pH 12 以上は $\mathrm{NaOH}$ )

O: $0-, \Delta: m-, \square: p-ク レ タ-ル$

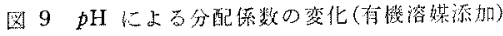

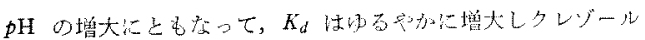

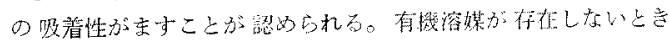

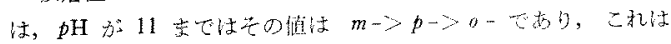

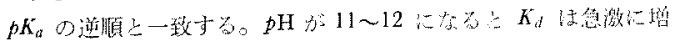

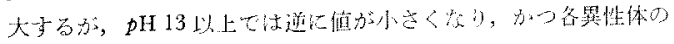

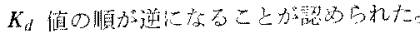

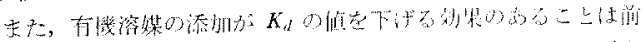

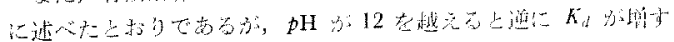

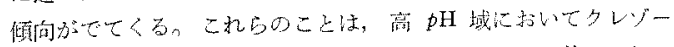

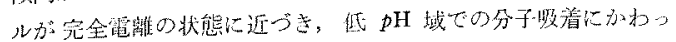

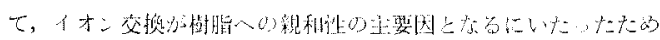
と䑾导れ五。

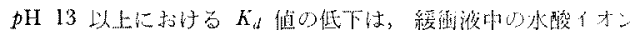

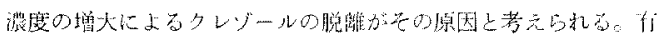

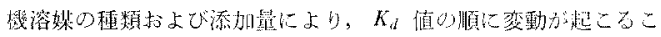

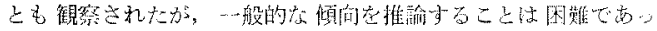
$t_{0}$

3.5 クレゾールのカラムクロマトグラフィー

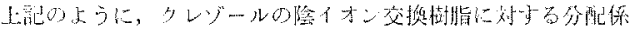

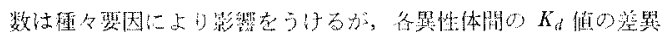

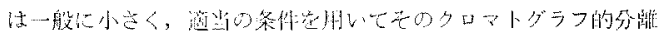

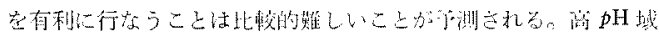

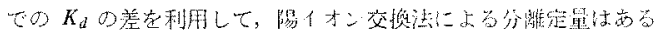

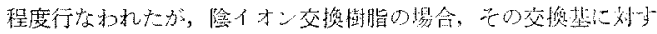

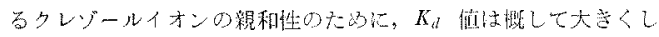

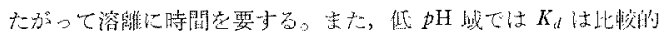

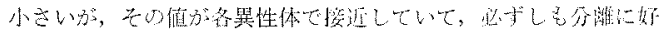

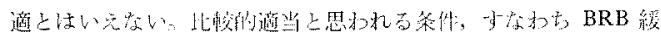

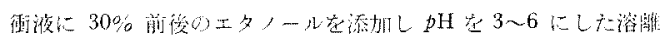

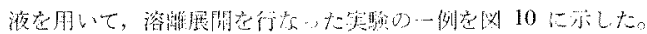

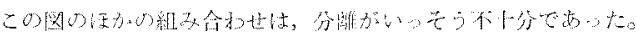

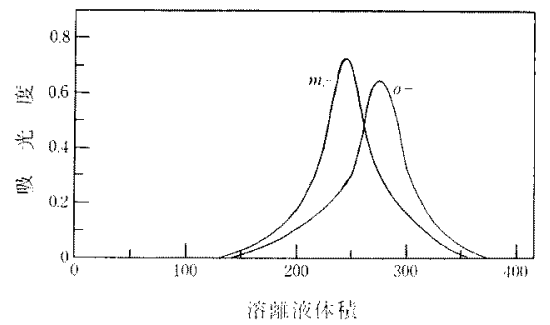

4 If: Amberlite GG-400, IYpe IOA $t_{3}=L_{\mathrm{a}}$ : $0.9 \times 30 \mathrm{~cm}$

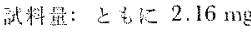

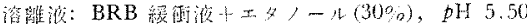

国 $100-, m-$ 名

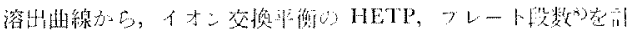

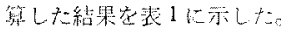

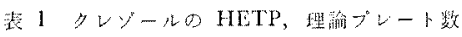

$\rightarrow \neg \Delta$ 展 $(\mathrm{cm})$

舅性 体 10

30

\begin{tabular}{|c|c|c|c|c|}
\hline HETP (cm) & 1.43 & 2.36 & 0.26 & 0. \\
\hline 理期俞ブレート数 & 6.99 & 4.24 & 150.8 & 115.8 \\
\hline$\Delta v / w_{1 / 2}^{!}$ & \multicolumn{2}{|c|}{0.4} & \multicolumn{2}{|c|}{0.7} \\
\hline
\end{tabular}

$\Delta v / w^{\prime} / 2$

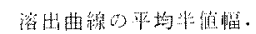

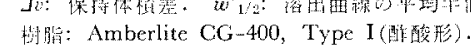

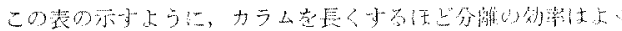

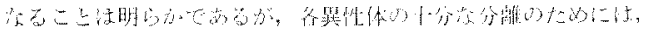

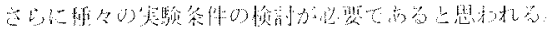

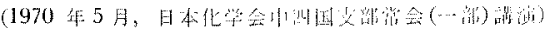

8) O. Samuelson, 尖酸 5) 0 p. 129 . 